\title{
Abdominal wall healing in incisional hernia using different biomaterials in rabbits ${ }^{1}$
}

\author{
Ana Letícia Gomes Aramayo, Gaspar de Jesus Lopes Filho" ${ }^{\mathrm{II}}$, Cirênio de Almeida Barbosa ${ }^{\mathrm{III}}$, Vânia da Fonseca Amaral ${ }^{\mathrm{IV}}$, \\ Luciano Assis Costav \\ ${ }^{\mathrm{I}}$ Fellow Master degree, Postgraduate Program in Interdisciplinary Surgical Sciences, Paulista Medical School, UNIFESP, Sao Paulo-SP, Brazil. \\ Intellectual and scientific content of the study, protocol design, technical procedures, acquisition and interpretation of data, statistical analysis, \\ manuscript writing. \\ IIPhD, Full Professor, Gastrointestinal Division, Paulista Medical School, UNIFESP, Sao Paulo-SP, Brazil. Conception of the study, interpretation of \\ data, statistical analysis, manuscript writing, critical revision. \\ IIIPhD, Associate Professor, Surgery Department, University of Medical Sciences of Minas Gerais, FCMMG, Belo Horizonte-MG, Brazil. Conception \\ and design of the study, interpretation of data, critical revision.

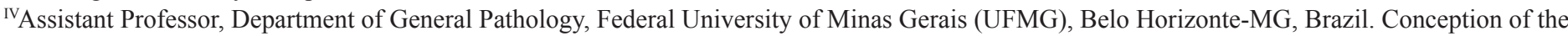 \\ study, histological analysis, critical revision. \\ ${ }^{\mathrm{v}}$ Graduate student, FCMMG, Belo Horizonte-MG, Brazil. Technical procedures, acquisition and interpretation of data.
}

\section{ABSTRACT}

PURPOSE: To investigate abdominal wound healing using specific biomaterials in incisional hernias.

METHODS: Incisional hernias were produced in 40 rabbits, after that they were reoperated with or without the use of meshes: PREMILENE $^{\circledR}$ (PPL), ULTRAPRO ${ }^{\circledR}$ (UP), PROCEED ${ }^{\circledR}$ (PCD) or repairing without mesh (TRANSPALB). After 30 days a macroscopic and microscopic study of the part withdrawn from the abdominal wall was performed.

RESULTS: Macroscopic: adhesion Area: PPL $>$ UP and PCD ( $p=0.031)$. Vascularization: PPL $>$ UP and PCD ( $p=0.001)$. PPL groups $(p=0.032)$ and PCD $(p<0.001)$ showed greater meshes shrinkages when compared to UP. Microscopic: neutrophils: PCD> PPL, UP and TRANSPALB $(\mathrm{p}=0.010)$; eosinophils: PPL $>$ UP, and TRANSPALB PCD $(\mathrm{p}=0.010)$; granulation tissue: PPL and PCD $>$ UP and TRANSPALB $(p<0.001)$; macrophages : PPL, UP and PCD $>$ TRANSPALB $(p<0.001)$; lymphocytes: PPL and PCD $>$ UP $(p=0.009)$ and TRANSPALB $(\mathrm{p}<0.001)$; giant cells: PPL, UP and PCD $>$ TRANSPALB $(\mathrm{p}<0.001)$; viscera adhered: PPL and UP $>$ PCD and TRANSPALB $(\mathrm{p}<0.001)$.

CONCLUSION: All types of meshes caused the formation of adhesions. The UP and PCD groups showed lower area and vascularization of the adhesions. The PPL and PCD groups showed higher meshes shrinkage and there was a predominance of acute inflammatory process in the PCD group.

Key words: Wound Healing. Abdominal Wall. Hernia, Ventral. Surgical Mesh. Adhesions. Biomaterials. Materials Testing. Animal Experimentation. Rabbits 


\section{Introduction}

The incisional hernia (IH) has ventral hernia or eventration as synonyms and it consists in the viscera protrusion through orifices or areas of the abdominal wall abnormally weakened by trauma and surgical incisions ${ }^{1}$. The IH incidence varies from 10-20\% and at least one in ten patients develops ventral hernia after undergoing median laparotomy. One third of these patients presented aesthetic problems, intestinal obstruction or acute strangulation that demand hernia repair ${ }^{2}$. Hernia recurrence is among the most troublesome outcomes after hernia repairing, showing progressive increase of recurrence after repeated repairing ${ }^{3}$. Approximately 31 to 55\% repairs made without the use of prostheses may cause recurrence, however the positioning of a polypropylene mesh in direct touching with the intraperitoneal viscera is not recommended since this can form adhesions between viscera and fistulas that occurs in $80-90 \%$ of patients ${ }^{4}$.

In the presence of large flaws in the abdominal wall, it is not always possible to separate the viscera from the meshes, so they are placed in the intraperitoneal position ${ }^{5}$.

From the eighties on, expanded polytetrafluoroethylene (ePTFE) meshes were largely used due to a lesser tissue reaction and the formation of adhesions ${ }^{6}$.

Technological improvement created coated meshes with absorbable layers to inhibit adhesions formation. Experimental studies show the effectiveness of using a mesh that is partially absorbing, constituted of four layers: one of low-density polypropylene between two-bladed absorbable (PDS) and one layer of oxidized regenerated cellulose, and plant origin raw materials with four to six months of absorption in order to prevent adhesions (PROCEED $\left.{ }^{\circledR}\right)^{7}$.

Another partially absorbable mesh is the lowdensity monofilament mesh constituted by two layers: lowdensity polypropylene/ poliglecaprone $\left(\mathrm{ULTRAPRO}^{\circledR}\right)$. The poliglecaprone layer incorporated to the low-density polypropylene mesh is reabsorbed in approximately 90 days.

The use of hernial sac as a reinforcement of the abdominal wall came as an alternative to the treatment of IH. It is a tissue constituted by the peritoneum, transverse fascia, fibrous tissue, collagen and part of the aponeurosis. It was verified that the hernial sac contains young fibroblasts and an expressive amount of smooth muscle fibers, followed by neovascularization that preserve the vitality of graft tissue ${ }^{1}$.

This study aims at verifying the healing of the abdominal wall of rabbits concerning incisional hernia repair using specific biomaterials: polypropylene mesh, low-density polypropylene mesh coated with poliglecaprone, low-density polypropylene mesh coated with absorbable polydioxanone and oxidized regenerated cellulose and repair without mesh, using the TRANSPALB technique (bilateral peritoneum aponeurotic transposition BLPAT).

\section{Methods}

Forty (40) New Zealand male white rabbits (Oryctogalus cuniculus) weighing from $2.800 \mathrm{~g}$ to $3.200 \mathrm{~g}$ were studied.

This research was done at Experimental Surgery Division, Surgery Department of the University of Medical Sciences of Minas Gerais (FCMMG), according to the recommendations of the international guidelines for animal protection and the Brazilian College of Animal Experimentation (COBEA). The study was approved by the Ethics Committee for Animal Experimentation of FCMMG and by the Ethics Committee in Research of the Federal University of Sao Paulo (UNIFESP).

Three prostheses were used (Table 1):

1- High-density polypropylene (HDP).

PREMILENE $^{\circledR}$ (B. Braun Aesculap, Tuttlingen/Germany).

2- Low-density polypropylene coated with poliglecaprone (UP). ULTRAPRO ${ }^{\circledR}$ (Johnson \& Johnson, U.S.A.).

3- Low-density polypropylene mesh coated with absorbable polydioxanone and oxidized regenerated cellulose (PCD). PROCEED ${ }^{\circledR}$ (Johnson \& Johnson, U.S.A.)

TABLE 1 - Features of the meshes researched.

\begin{tabular}{cccc}
\hline & PROCEED & ULTRAPRO & POLYROPYLENE \\
\hline WEIGH/AREA & $44 \mathrm{~g} / \mathrm{m}^{2}$ & $28 \mathrm{~g} / \mathrm{m}^{2}$ & $80-95 \mathrm{~g} / \mathrm{m}^{2}$ \\
PORE SIZE & $2 \mathrm{~mm}$ & $4 \mathrm{~mm}$ & $0.6 \mathrm{~mm}$ \\
THICKNESS & $0.7 \mathrm{~mm}$ & $0.5 \mathrm{~mm}$ & $0.6 \mathrm{~mm}$ \\
\hline
\end{tabular}

The animals were allocated in individual cages with rabbit ration (Guabi ${ }^{\circledR}$, Belo Horizonte-MG) and water ad libitum.

\section{Anesthesia and analgesia}

The rabbits were anesthetized with Ketamine 10\%(60 - 80 $\mathrm{mg} / \mathrm{Kg})$ and Xylazine $\%(8-15 \mathrm{mg} / \mathrm{Kg})$, intramuscular injection. Meloxicam anti-inflammatory was given subcutaneously (2 mg/ $\mathrm{kg}$ ) in the immediate postoperative period and 12 hours after the procedure. 


\section{Incisional hernia experimental surgery technique}

After the anesthetic procedure all animals were trichotomized in the abdominal region and the abdominal antisepsis was performed with degerming povidone.

All rabbits underwent a median laparotomy with $6 \mathrm{~cm}$ of extension with a cranial distal extremity of $9 \mathrm{~cm}$ from the xiphoid process. It was performed a subcutaneous displacement of the mesh by approximately $1,5 \mathrm{~cm}$ in each side of the midline. Next, a $5 \mathrm{~cm}$ longitudinal incision from the linea alba was performed and another transversal incision in each corner, measuring $1 \mathrm{~cm}$, including muscle, aponeurosis and peritoneum to create a hernial orifice. Next, a suture was performed with simple stitching using polyglycolic acid thread 4-0 to all muscular aponeurotic system to the subcutaneous mesh and to the dermis, reversing the edges to force this system to be permanently open. To conclude this operative procedure the skin synthesis was made with continuous stitching of nylon 4-0 $0^{8}$ (Figure 1).
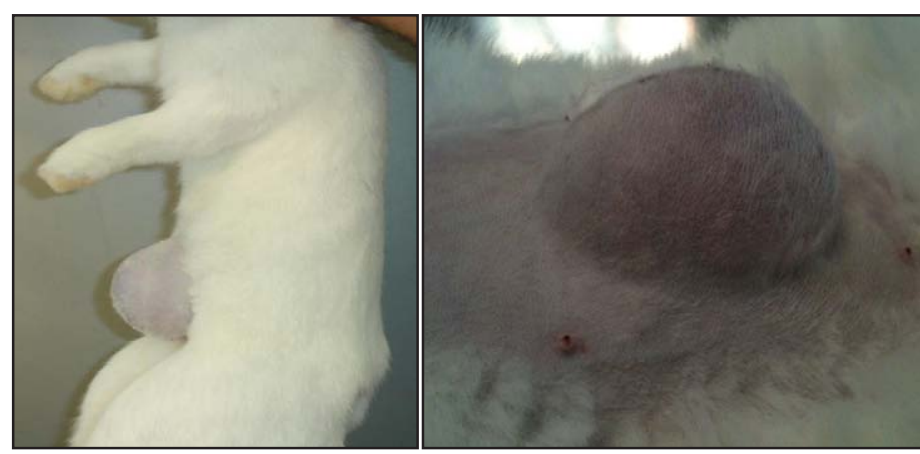

FIGURE 1 - Incisional hernia formed after 30 days.

\section{Experimental hernia repair surgical technique}

After 30 days, all rabbits were distributed randomly and reoperated. In the PPL, UP and PCD groups, meshes measuring $7 \times 5 \mathrm{~cm}$ were placed in the intraperitoneal position and then fixed with 6 " $U$ " stitches made of polypropylene 4-0 thread, involving all layers of the total abdominal wall to $0.5 \mathrm{~cm}$ of distance of the hernial sac edge, following the cavity closure.

In the control group, the TRANSPALB technique was performed through the median opening of the hernial sac to beyond the hernial ring edges, creating two peritoneal fibrous lateral snips. A suture was done using a polypropylene 4-0 thread from the hernial sac edge in one of the straight abdominal muscles to the peritoneum and the posterior lamina of the rectus sheath, creating the medial snip. An incision was done in the anterior lamina of the rectus abdominal muscle sheath in the opposite side to the posterior opening, approximately $2 \mathrm{~cm}$ of the medial edge, creating two more snips. The medial snip of the abdominal rectus sheath was sutured with the contralateral posterior medial snip, forming an intermediate layer of an imbrication of the three layers. The fibrous peritoneum snip was sutured with the anterior lateral snip of the rectus sheath. All layers were sutured with continuous stitches of polyglactin 4.0 thread $^{1}$.

In all groups only the excess of the hernial sac was resected after it has been dissected from the dermoepidermal snip. The skin was sutured with a continuous suture of polyamide 4.0 thread.

In the 60th postoperative day all rabbits were anesthetized with the same dose of ketamine and xylazine used in the previous operation, followed by euthanasia made with $19.1 \%$ intravenous potassium chloride injection. Then, all the anterior abdominal wall was removed together with the scar through an inverted "U" incision and the removed parts were placed into a $10 \%$ formaldehyde solution.

\section{Macroscopic analysis of healing}

The healing was evaluated macroscopically through the clinical analysis, following these criteria9:

a) Presence of hematoma in the place where the surgical mesh was fixed in the abdominal wall: grade $0=$ absent and grade $1=$ present;

b) Junction between the surgical mesh and the abdominal wound edge: grade $0=$ joined; grade $1=$ partial dehiscence and grade 2 = total dehiscence;

c) Presence of infection the surgical site being: grade $0=$ absent; grade 1 = mild infection and grade 2 = abscess;

d) Presence of visceral fistulae using the surgical mesh: grade $0=$ absent and grade $1=$ present;

e) Study of the presence of adhesions inside the abdominal cavity through the score to evaluate adhesions $(0-4)^{5}$ : 
TABLE 2 - Adhesion scoring scale.

\begin{tabular}{|c|c|c|c|c|c|}
\hline Parameter & Score & & & & \\
\hline & 0 & 1 & 2 & 3 & 4 \\
\hline $\begin{array}{c}\text { Adhesion } \\
\text { vascularization }\end{array}$ & No & Yes & - & - & - \\
\hline
\end{tabular}

(scale of $0-12$ )

f) Presence of visceral hernia: grade $0=$ absent and grade $1=$ present.

\section{Calculation of meshes area}

The value of the meshes areas were calculated with three digits after the decimal point with deviation less than $0.2 \%$.

The calculation process followed these steps:

1. Creation of $2 \mathrm{D}$ polygons in Autocad Engineering Software.

2. Creation of a surface inside the created polygon.

3. Measurement with the software resource (3 digits after the decimal point).

\section{Microscopic analysis}

The microscopic evaluation of the surgical pieces was done at the Pathology Department at UFMG. Some staggered cuts were done in the surgical pieces and two fragments measuring around $2.0 \mathrm{~cm}$ long were chosen, reaching the full-thickness of the abdominal wall.

The material was processed to be included in paraffin, and histological cuts of 5.0 micrometers were stained by the usage of hematoxylin and eosin (HE) and by Gomori's Trichrome. They were examined in an ordinary light microscope of 40x, 100x and 400x enlargement.

Findings were subjectively graduated by the same absent observer, rare / scarce $(+)$, small amount $(++)$, moderate amount $(+++)$ and large amount $(++++)$. It was evaluated: inflammatory infiltrate and its constitution (neutrophils, eosinophils, granulation tissue, giant cells, macrophages, and lymphocytes), amount of fibrosis and mesothelial reaction.

\section{Statistical analysis}

An extension of Fisher's exact test was done to compare the adhesion score and histological evaluation; the Variance Analysis with a Fixed Value to compare the total score between the groups with meshes, from the percentage reduction of the mesh area and usage of Tukey's method whenever necessary. The significance level is equal to $5 \%$ and the Statistical Package for the Social Sciences Software (SPSS) was used.

\section{Results}

There was no presence of seroma, hematoma, infections of the surgical site, fistulous tract, hernia recurrence or mesh extrusion.

In two animals from the PCD group it was observed the presence of yellowish nodules located between the mesh and the viscera, suggesting a reaction against a foreign body.

In all animals, the meshes were well integrated to the abdominal wall.

There were no deaths.

Some aspects of the adhesions were evaluated through the adhesions score, like the area of the adhesion, vascularization, size, separation strength and total score were evaluated in the rabbits from the PPL, UP, PCD and TRANSPALB groups (Figures 2 to 4$)$.

The size of the adhesion $(\mathrm{p}=0.134)$ and the separation strength $(p=0.083)$ were not statistically significant among the groups PPL, UP and PCD.

One should have in mind that the aspects related to adhesion were compared only among the groups PPL, UP and PCD, since the TRANSPALB group has not displayed any adhesion.

Concerning the total score there was not any significant 
statistic when comparing the three mesh groups $(\mathrm{p}=0.064)$.

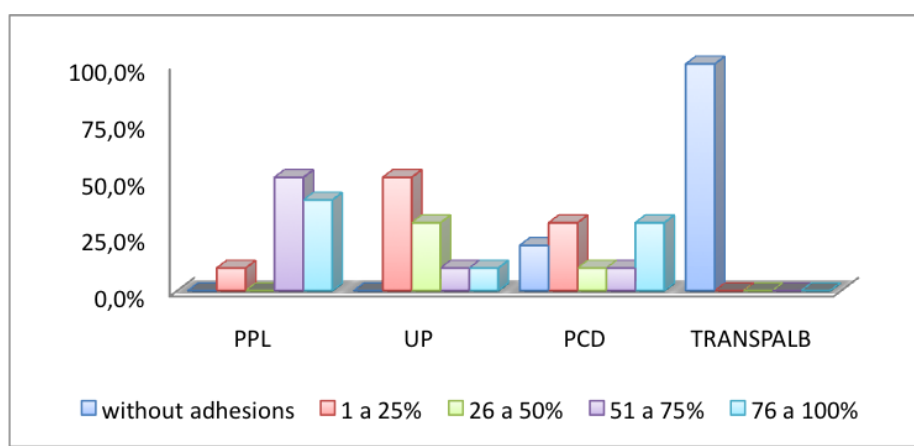

FIGURE 2 - Distribution of the adhesion area evaluated in rabbits from groups PPL, UP, PCD and TRANSPALB (PPL $>$ UP and PCD, $\mathrm{p}=0.031$ ).

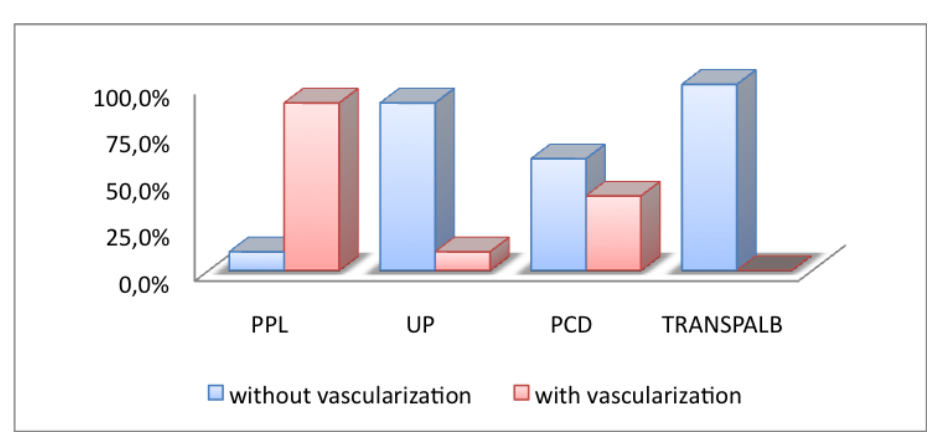

FIGURE 3 - Distribution of the adhesion vascularization evaluated in rabbits from groups PPL, UP, PCD and TRANSPALB (PPL $>$ UP and PCD, $\mathrm{p}=0.001$ ).

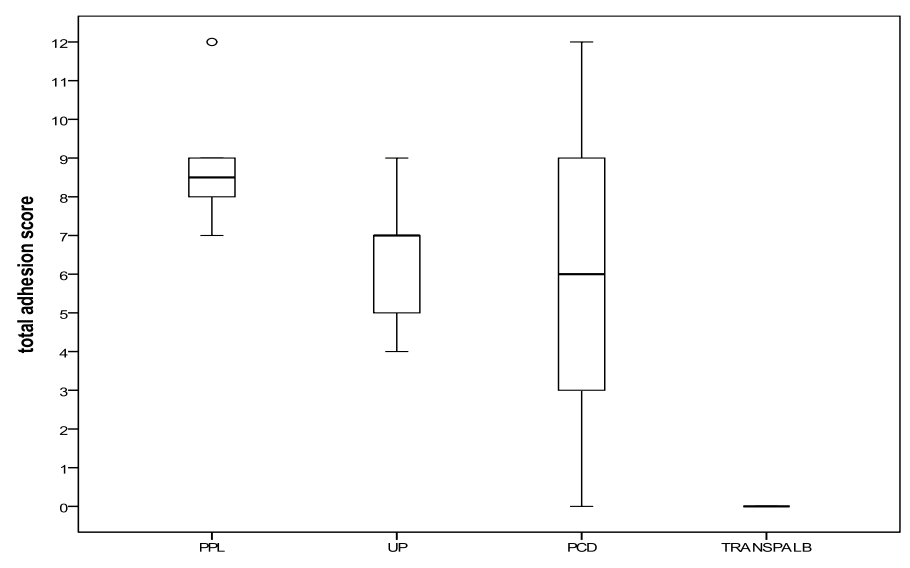

FIGURE 4 - Total score of Boxplot of adhesion evaluated in rabbits from groups PPL, UP, PCD and TRANSPALB.

\section{Analysis of the area reduction of the meshes}

Only the PPL, UP and PCD groups had the areas of the used meshes measured (Figure 5).

For all rabbits there was a shrinkage on the mesh area, and the percentage of the shrinkage was not the same among the three groups $(\mathrm{p}<0.001)$.

The PPL $(\mathrm{p}=0.032)$ and PCD groups $(\mathrm{p}<0.001)$ displayed larger shrinkage when compared to the UP group.
The PPL group displayed the same area percentage of shrinkage when compared to the PCD group $(\mathrm{p}=0.130)$, and the UP group displayed the smallest shrinkage.

The PPL group displayed a median shrinkage of $40.7 \%$ of the meshes and the UP group displayed a median reduction of $24.3 \%$. The PCD group displayed a median reduction of $53 \%$.

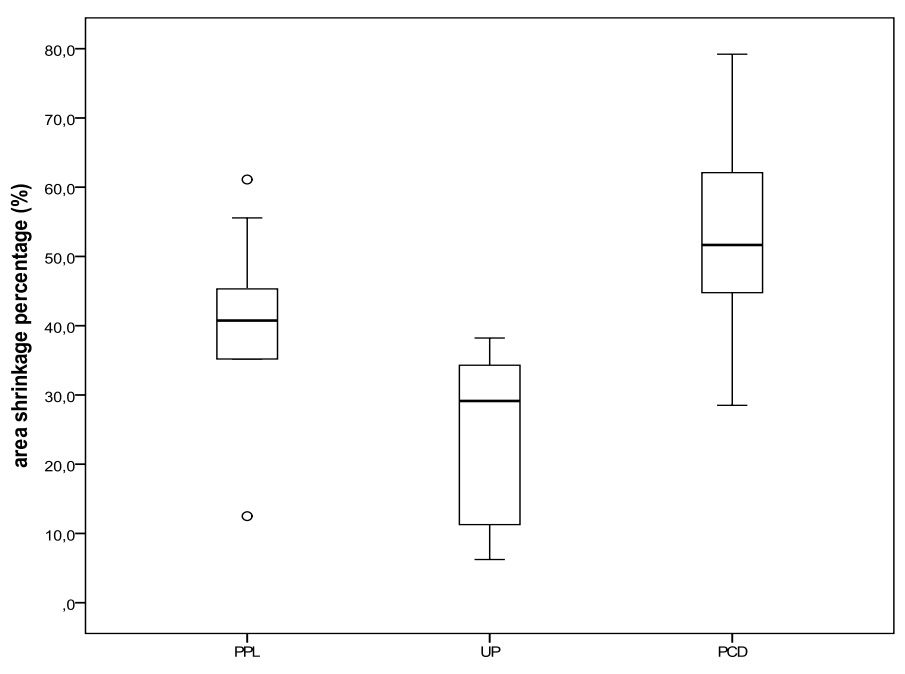

FIGURE 5 - Boxplot of the area percentage shrinkage in rabbits from the PPL, UP and PCD groups.

\section{Microscopic analysis}

All samples displayed reaction to suture threads (chronic inflammatory process with gigantocellular reaction of the foreign body type related to suturing thread remnants).

The inferential analysis using the extension of Fisher's exact test has revealed that fibrosis $(\mathrm{p}=0.353)$ and the mesothelial reaction ( $p=0.061$ ) were not significantly associated to the groups. On the other hand, lymphocytes presence $(\mathrm{p}<0.001)$, macrophages $(p<0.001)$, neutrophils $(p=0.040)$, eosinophils $(p=0.014)$, giant cells $(p<0.001)$, granulation tissue $(p=0.003)$ and adhered viscera $(\mathrm{p}<0.001)$ were statistically associated to the investigated groups (Figures 6 to 14).

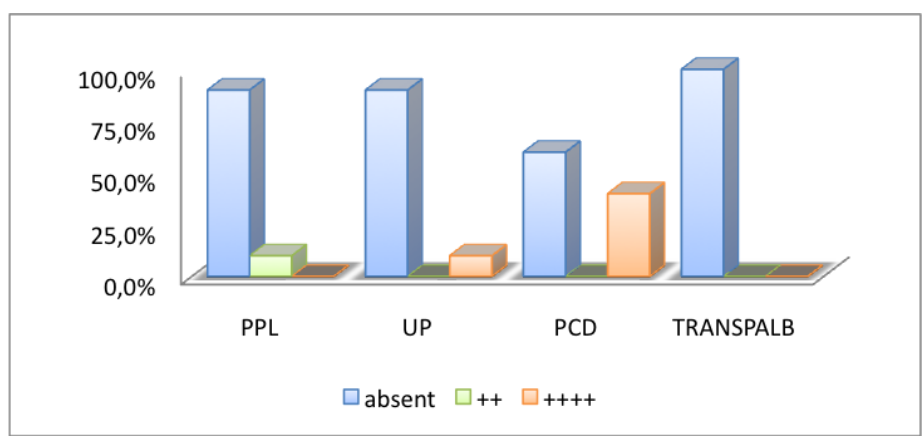

FIGURE 6 - Distribution of the neutrophils presence evaluated in rabbits from the PPL, UP, PCD and TRANSPALB groups (PCD $>$ PPL, UP and TRANSPALB, $\mathrm{p}=0.010$ ). 


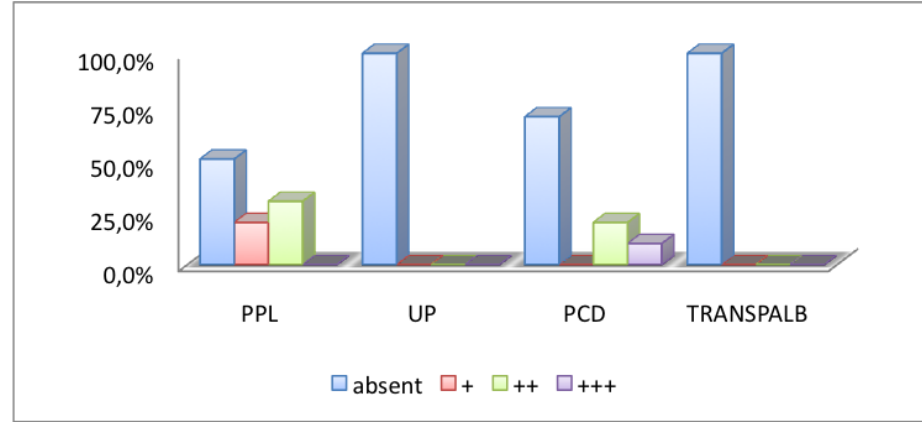

FIGURE 7 - Distribution of the eosinophils presence evaluated in rabbits from PPL, UP, PCD and TRANSPALB groups (PPL $>$ UP, PCD and TRANSPALB, $\mathrm{p}=0.010$ ).

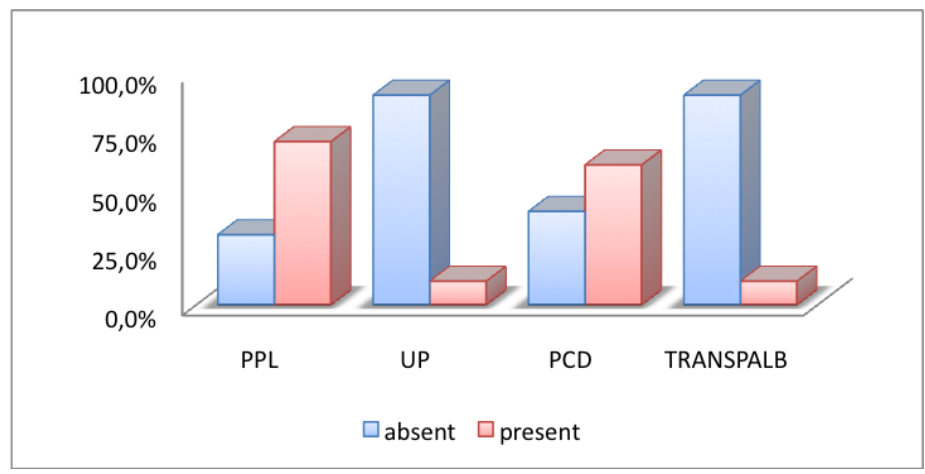

FIGURE 8 - Distribution of granulation tissue presence evaluated in rabbits from the PPL, UP, PCD and TRANSPALB groups (PPL and PCD $>$ UP and TRANSPALB, $\mathrm{p}<0.001)$.

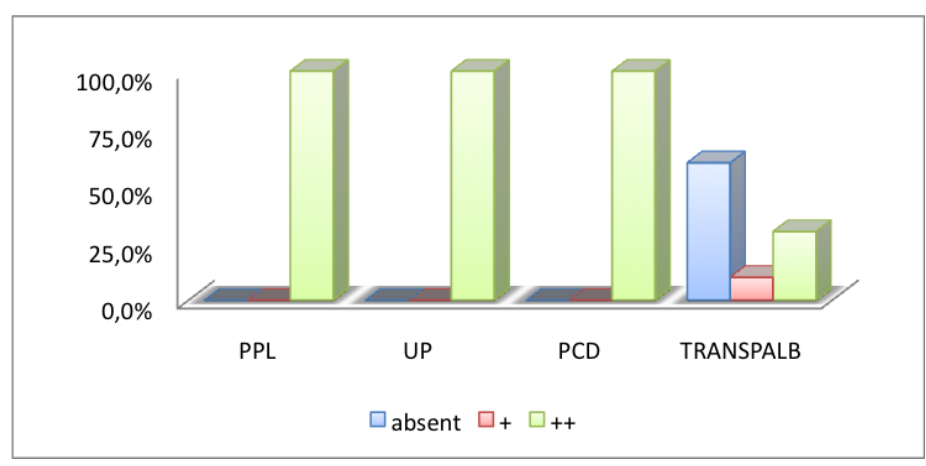

FIGURE 9 - Distribution of macrophage presence evaluated in rabbits from the PPL, UP, PCD and TRANSPALB groups (PPL, UP and PCD $>$ TRANSPALB, $\mathrm{p}<0.001$ ).

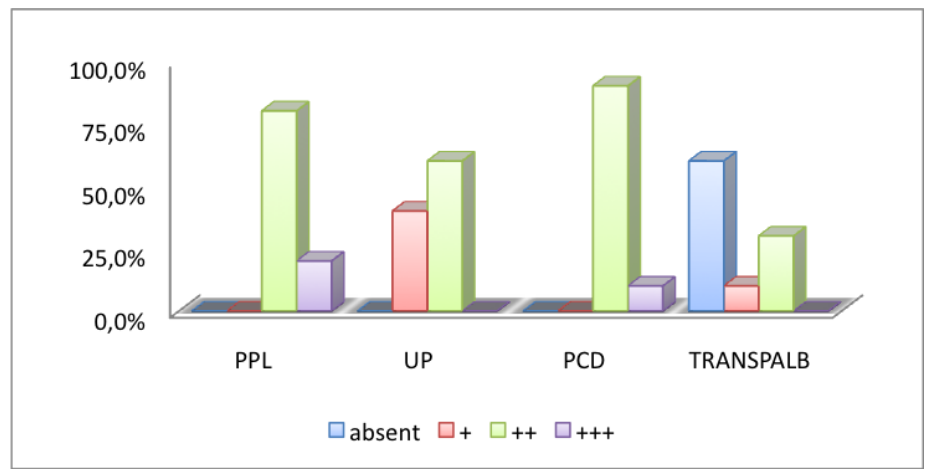

FIGURE 10 - Distribution of the lymphocytes presence evaluated in rabbits from the PPL, UP, PCD and TRANSPALB groups (PPL and PCD $>$ UP, $p=0.009$ and TRANSPALB, $p<0.001$ ).

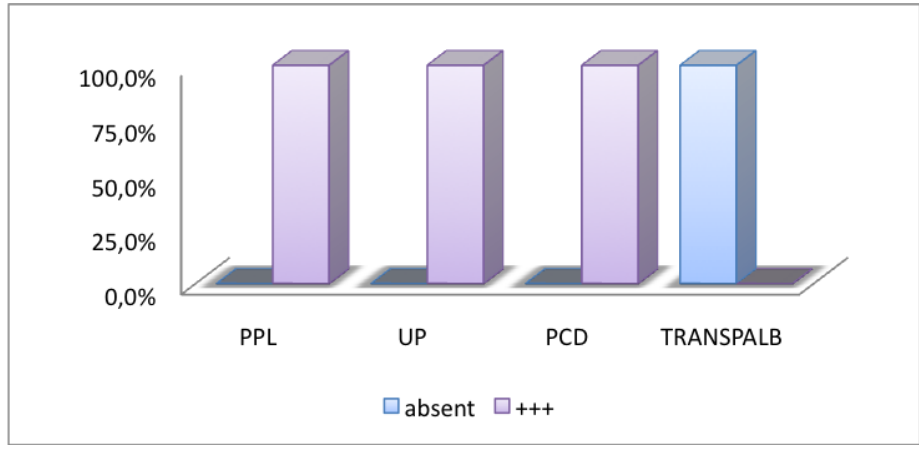

FIGURE 11 - Distribution of giant cells presence evaluated in rabbits from the PPL, UP, PCD and TRANSPALB groups (PPL, UP and PCD $>$ TRANSPALB, $\mathrm{p}<0.001$ ).

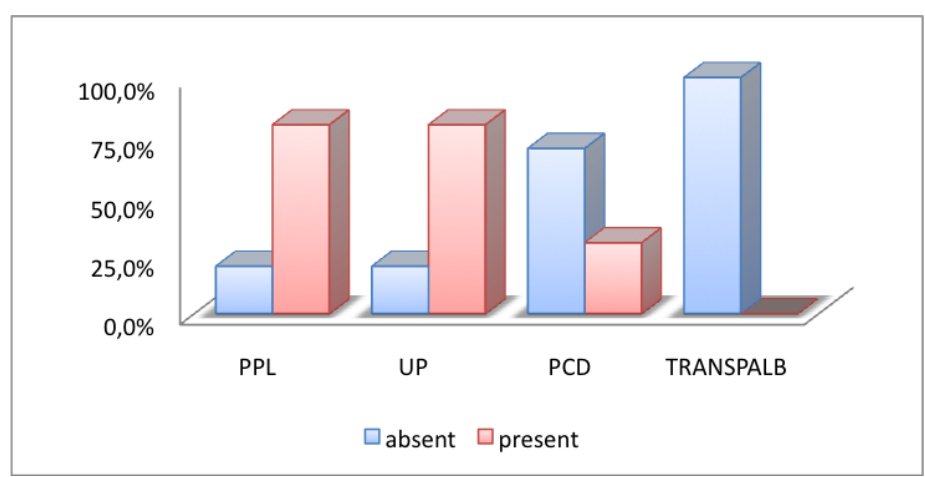

FIGURE 12 - Distribution of viscera adhesion evaluated in rabbits from the PPL, UP, PCD and TRANSPALB groups (PPL and UP > PCD and TRANSPALB, $\mathrm{p}<0,001)$.

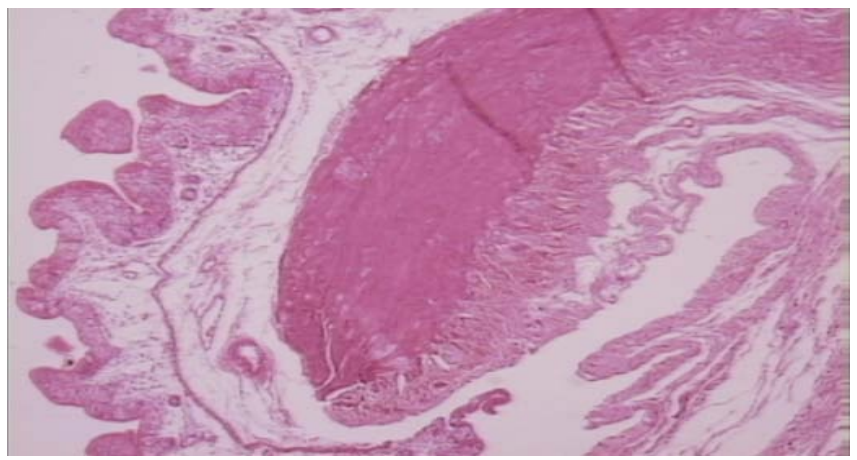

FIGURE 13 - ULTRAPRO ${ }^{\circledR}$ mesh adhesion to the intestinal wall (HE40x).

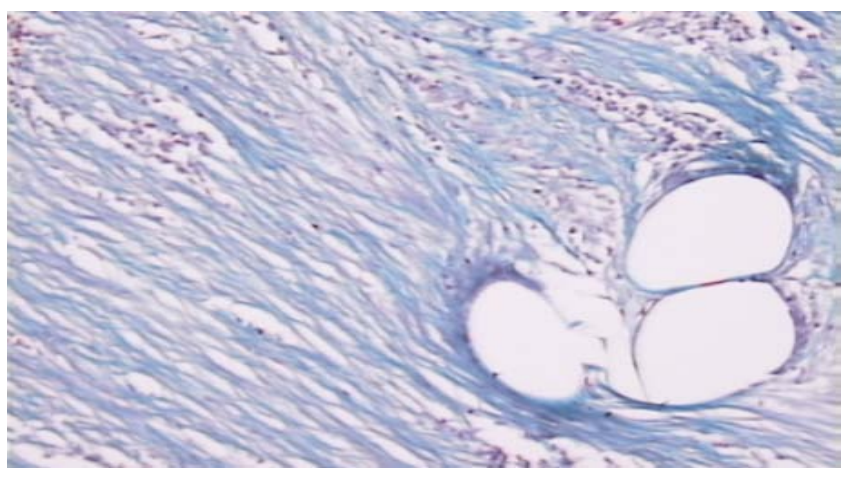

FIGURE 14 - PROCEED ${ }^{\circledR}$ mesh in negative image, peripheral giant cell, fibrosis (collagen colored in green), inflammatory infiltrate (Gomori's trichrome-100x). 


\section{Discussion}

Some features are important when choosing the adequate kind of mesh. The polypropylene mesh has either low density or high density. High density meshes have higher tensile strength and are stronger than low density meshes. The use of heavier meshes is associated to the increasing of complications and adverse events as fistulas, adhesions formation and pain. Although these complications are commonly observed when the mesh is intraperitoneally inserted, they are also observed when they are inserted extraperitoneally ${ }^{10}$.

Heavy weight meshes have a larger surface area and they produce more intense foreign body reaction. They also tend to shrink more than the lightweight meshes besides being more rigid; this can lead to more difficulty in the abdominal movements. The lightweight meshes are referred with larger pores resulting in a smaller surface area and smaller reaction to foreign body and fibrosis ${ }^{11}$.

Cobb et al. ${ }^{12}$ have categorized the polypropylene mesh $\left(\right.$ Marlex $\left.^{\circledR}\right)$ as heavy weight $\left(95 \mathrm{~g} / \mathrm{m}^{2}\right)$ and pore size of $0.6 \mathrm{~mm}$; the polypropylene mesh (Prolene ${ }^{\circledR}$ ) being median weight $\left(45 \mathrm{~g} / \mathrm{m}^{2}\right)$ and pore size of $2.4 \mathrm{~mm}$ and the lightweight (Ultrapro ${ }^{\circledR}$ ) $28 \mathrm{~g} / \mathrm{m}^{2}$ with pore size of $4 \mathrm{~mm}$. Moreover, he studied the mesh shrinkage measure in pigs using digital planimetrics in which the edges of the meshes were drawn with a planimeter and digital reading of the surface with a margin of error of $\pm 0.2 \%$.

Concerning the technique without the use of a mesh, the bilateral longitudinal peritoneum aponeurotic transposition - BLPAT, it is claimed that it minimizes the adverse events of synthetic meshes use besides the difficulty of getting meshes in that time of its invention. It is indicated to large incisional hernias and it uses the hernial sac as a reinforcement of the abdominal wall. This is an alternative technique to the therapeutic arsenal. It uses tissue from the own surgical field of hernia repair without costs and possibilities to cause an immunological reaction. It can point out to the possibility of stem cells behavior in future researches ${ }^{1}$.

The hernial sac constitution presents an exuberance of smooth muscle fibers in its wall close to a dense fibrous tissue and it can lead to tissue transformation into aponeurotization. This technique allows an anatomo-functional result once it reestablishes the rectus abdominal muscle and the linea alba ${ }^{1}$.

As this technique does not use prosthesis, we have decided to include it as a control group, also considering the fact of being a standard technique in our service.

Adhesions formation has been one of the most extensively studied themes in the surgical area, but its physiopathology still lacks for conclusive data. The insult to the mesothelial cell would be the main trigger; it could be caused by a variety of stimuli (trauma, ischemia, dissection, foreign body and so on). After an initial insult, an inflammatory response begins and remains during 24-48 hours. After 5-7 days, proliferating fibroblasts infiltrate through a fibrin web, collagen and other protein connective tissues are deposited and the neovascularization occurs in order to produce the fibrous adhesion and the production of new mesothelial layer. This layer is resistant to new adhesions formation. The mesothelial cells generally origin in the same way of the adhesion surfaces. They appear from denude area in the peritoneum. The postoperative adhesion formation process begins during the surgery and it can intensify for weeks or months. The time due to the complete development of the adhesion may vary from five to seven weeks followed by the peritoneal aggression. Due to that, a non-adhesive layer molten to the prostheses must be nontoxic, well tolerated in the abdomen and above all it needs to prevent the fixation of viscera on the mesh surface ${ }^{4}$.

Using polypropylene meshes, expanded polytetrafluoroethylene, polypropylene/ oxidized regenerated cellulose and polypropylene/ expanded polytetrafluoroethylene in an experiment with rabbits it was observed the presence of adhesions formed within one week and their permanence until the end of 16 weeks of observation. The authors observed that the polypropylene mesh caused the formation of firmer adhesions with larger area than the other meshes $(\mathrm{p}<0.05)^{7}$.

According to Jacob et al. ${ }^{13}$, the adhesions were thinner in the multifilament polyester/cellulose/ collagen group than in the polypropylene/ oxidized regenerated cellulose $(p<0.007)$. The collagen layer in the multifilament polyester/cellulose/ collagen mesh was more effective to prevent adhesions than the polydioxanone one.

The median density polypropylene, polyester, polypropylene/ polyglactin 910, polypropylene/ oxidized regenerated cellulose and polytetrafluoroethylene meshes were evaluated after 30 days of the implantation in the peritoneal cavity of rabbits. It was observed that the grade of adhesions was significantly smaller in the polypropylene/ oxidized regenerated cellulose and polytetrafluoroethylene groups when compared to the other groups in the study 5 .

Experiments with rats using six types of meshes in the intraperitoneal position evaluated after seven to 30 days concluded that the absorbable layers on the meshes surface are capable of preventing adhesions in seven days but this effect decreases in 30 days and expressive adhesions on the surface of the meshes can be observed ${ }^{2}$. 
In experiments with rabbits the polypropylene/ polyester/ cellulose/ collagen, polypropylene/ oxidized regenerated cellulose and expanded polytetrafluoroethylene meshes were evaluated. For the four types it was observed the equivalence in the adhesions of these materials in this animal model. The polypropylene/ polyester/ cellulose/ collagen group displayed less adhesions score when compared to the other three types of meshes $(\mathrm{p}=0.02)$. All meshes showed rigidity and rupture of energy equivalence when using the tensiometer ${ }^{14}$.

In our study, the formation of adhesions was shown in all types of meshes used, even in the types having a protector barrier. On the other hand, the UP and PCD groups exhibited fewer adhesions areas and less vascularization in these areas. The PPL group showed a larger area of adhesions and also greater adhesion vascularization when compared to the UP and PCD groups.

The study of prosthesis retraction and the extension of this retraction have great importance considering that the surgeon could leave a proper safety margin around the mesh allowing repair without tensioning and preventing to pull along the mesh.

Klinge et al. ${ }^{15}$ compared the percentage of shrinkage of a low density polypropylene and polyglactin 910 mesh. In a model with dogs, they have shown that all polypropylene mesh shrinks from $30 \%$ to $50 \%$ of its original size after $2-6$ months of the implantation. The low density mesh resulted in less inflammatory response and a reduction on the size of $34 \%$ of its original size compared to the $46 \%$ of contraction in the polypropylene standard mesh.

The expanded polytetrafluoroethylene mesh had greater reduction in its area than the polypropylene/ oxidized regenerated cellulose, polypropylene/ expanded polytetrafluoroethylene and polypropylene $(\mathrm{p}<0.0001)$ mesh, as demonstrated in experimental study with rabbits ${ }^{7}$.

The polypropylene/ oxidized regenerated cellulose, polypropylene/ expanded polytetrafluoroethylene and polypropylene meshes were analyzed through a randomized study and through a laparoscopy in pigs. After 28 days, the authors observed that the polypropylene/ oxidized regenerated cellulose mesh displayed bigger retraction than the polypropylene/ expanded polytetrafluoroethylene or the polypropylene type of meshes, although the difference was not statically significant ${ }^{13}$.

In a laparoscopic experiment with 18 pigs, the authors analyzed the biocompatibility of using low density polypropylene/ polyvinylidene fluoride, polypropylene/ oxidized regenerated cellulose and polypropylene/ polyester/ cellulose/ collagen meshes. The planimetrics analysis was done after four months and it showed bigger contraction in the polypropylene/ oxidized regenerated cellulose type of meshes than in the polypropylene/ polyvinylidene fluoride $(\mathrm{p}=0.03)$ and polypropylene/polyester/ cellulose/collagen meshes $(p=0.04)^{16}$.

The high density mesh with micropores presents lower risk of mesh-tissue adhesion but it presents encapsulation risk and foreign body reaction, it results in less integration of the mesh to the tissue and can lead to chronic pain. The low weight meshes with macropores are better incorporated, flexible and they show lower reaction to foreign body; however they displayed high risk of adhesions ${ }^{17}$.

After four months of the mesh implantation in pigs it was observed that the polypropylene/polyester/cellulose/collagen mesh showed local abscess. The collagen covering to the polypropylene mesh seems to confer important advantages in biocompatibility terms, with beneficial implications to the formation of adhesions and reduction in the size of the mesh despite the presence of infection being an important negative issue ${ }^{16}$.

Concerning the histological findings in our experiment, there was a predominance of the acute inflammatory process in the PCD group in our study. Neutrophils were found in $40 \%$ of rabbits from the PCD group. This finding is significantly higher than the other groups.

Harrell et al. ${ }^{18}$ made a histological study of intraperitoneal prosthesis and after four months observation they verified that the polypropylene/ oxidized regenerated cellulose mesh displayed smaller scar plaque than the polypropylene and polypropylene/ expanded polytetrafluoroethylene mesh; however the expanded polytetrafluoroethylene mesh had the smallest scar plaque but larger number of inflammatory cells like macrophages.

In an experiment with rats, it was observed that the polypropylene/ oxidized regenerated cellulose mesh type was surrounded by many macrophages degrading the cellulose covering with no granulation signal and fibroblasts inflow, this probably has led to the emerging of a large number of adhesions. The polypropylene/ poliglecaprone mesh was also similar to the polypropylene/ oxidized regenerated cellulose group ${ }^{2}$.

In our study, the PPL group showed higher presence of eosinophils in relation to the other groups, representing an acute phase and or hypersensibility in relation to the other groups.

The PPL and PCD groups showed larger presence of tissue granulation in relation to the UP and TRANSPALB groups, this could indicate greater posterior migration of fibroblasts. The UP group exhibited less presence of tissue granulation in relation to the others.

The three groups with meshes presented larger presence of macrophages, when compared to the group without mesh. 
Rosch et al. ${ }^{19}$ have shown that the response to the biomaterial inflammatory dependent is predominantly influenced by macrophages ${ }^{19}$. Jansen et al..$^{20}$ made an in vitro study confirming that the macrophage is the key of the mediator in foreign body reaction, being essential in the angiogenesis, inflammation and fibrosis known as critical processes in wound inflammation ${ }^{20}$.

In our experiment, the PPL e PCD meshes exhibited greater presence of lymphocytes concerning the UP mesh and the technique without mesh, this characterizes a chronic phase or a maturation phase of the healing.

Concerning the giant cells it was clear a larger number of them in the three groups with meshes, it was observed globules in the negative image involved by a gigantocellular reaction of the foreign body type.

Although there was no significance in the variable comparison of the mesothelial reaction in the four groups, the UP and PCD groups showed greater mesothelial reaction in relation to the PPL and TRANSPALB groups.

Concerning the variable of adhered viscera, the PCD group showed higher presence of them than the group without meshes, nevertheless the difference was not statistically significant. The PCD and TRANSPALB groups, when analyzed together, presented less adhered viscera in relation to the PPL and UP groups with significant statistical difference.

\section{Conclusions}

1. All types of meshes used in this study caused the formation of adhesions and the group without mesh didn't show any adhesions;

2. The groups ULTRAPRO ${ }^{\circledR}$ and PROCEED $^{\circledR}$ presented smaller areas of adhesion and less vascularization in these areas comparing to the PREMILENE ${ }^{\circledR}$ group;

3. Comparing the measures of the meshes area it was observed shrinkage in all meshes, and the groups PREMILENE $^{\circledR}$ and PROCEED ${ }^{\circledR}$ exhibited a higher shrinkage;

4. The inflammatory process either acute or chronic was higher in the PREMILENE ${ }^{\circledR}$ and PROCEED $^{\circledR}$ groups; however, it was observed the predominance of an acute inflammatory process in the PROCEED ${ }^{\circledR}$ group.

\section{References}

1. Silva AL, Barbosa CA, Souza PL, Vieira RG. Use of autologous hernia sac in the reinforcement of inguinal and incisional hernia plastic surgery. Rev Bras Med. 2004;61(5):273-86.

2. Schreinemacher MHF, Emans PJ, Gilbels MJJ, Greve JWM, Beets
GL, Bouvy ND. Degradation of mesh coatings and intraperitoneal adhesion formation in an experimental model. $\mathrm{Br} \mathrm{J}$ Surg. 2009;96(3):305-13.

3. Flum DR, Horvath, K, Koepsell, T. Have outcomes of incisional hernia repair improved with time? A population-based analysis. Ann Surg. 2003;237(1):129-35.

4. Gaertner WB, Bonsack ME, Delaney JP. Visceral adhesions to hernia prostheses. Hernia. 2010;14:375-81.

5. Kiudelis M, Jonciauskiene J, Deduchovas O, Radziunas A, Mickevicius A, Janciauskas D, Petrovas S, Endzinas Z, Pundzius J. Effects of different kinds of meshes on postoperative adhesion formation in the New Zealand White rabbit. Hernia. 2007;11(1):192.

6. Bauer JJ, Harris MT, Krell I, Gelernt IM. Twelve-year experience with expanded polytetrafluoroethylene in the repair of abdominal wall defects. Mout Sin J Med. 1999; 66:20-5.

7. Harrell GH, Novistsky YW, Peindl RD, William SC, Austin A. Prospective evaluation of adhesion formation and shrinkage of intraabdominal prosthetics in a rabbit model. Am Surg. 2006;72(9):80813 .

8. Aydos RD, Silveira IS, Magalhães AM, Goldenberg S. Um modelo de hérnia incisional em coelhos. Acta Cir Bras. 1997;12(3):189-92.

9. Pundek MRZ, Czeczko NG, Yamamoto CT, Pizzato RF, Czeczko LEA, Dietz UA, Malafaia O. Estudos das telas cirúrgicas de polipropileno/poliglecaprone e de polipropileno/polidioxanona/ celulose oxidada regenerada na cicatrização de defeito produzido na parede abdominal de ratos. ABCD Arq Bras Cir Dig. 2010;23(2):949.

10. Bringman S, Conze J, Cuccurullo D, Deprest J, Junge K, Klosterhalfen B, Parra-Davila E, Ramshaw B, Schumpelick V. Hernia repair: the search for ideal meshes. Hernia. 2010;14:81-7.

11. Klosterhalfen B, Junge K, Klinge U. The lightweight and large porous mesh concept for hernia repair. Exp Rev Med Dev. 2005;2:103-17.

12. Cob WS, Burns JM, Peindl RD, Carbonell AM, Mathews BD, Kercher KW, Heniford BT. Textile analysis of heavy weight, and light weight polypropylene mesh in a porcine ventral hernia model. J Surg Res. 2006;136:1-7.

13. Jacob BP, Hogle NJ, Durak E, Kim T, Fowler DL. Tissue ingrowth and bowel adhesion formation in an animal comparative study: polypropylene versus Proceed versus Parietex Composite. Surg Endosc. 2007;21:629-33.

14. Dolce CJ, Keller JE, Stefanidis D, Walters KC, Health JJ, Lincourt AL, Norton HJ, Kercher KW, Heniford BT. Evaluation of soft tissue attachments to a novel intra-abdominal prosthetic in a rabbit model. Surg Innov. 2012;19(3):295-300.

15. Klinge U, Klosterhalfen B, Müller M, Ottinger AP, Schumpelick V. Shrinking of polypropylene mesh in vivo: an experimental study in dogs. Eur J Surg. 1998;164(12):965-9.

16. Schug-Pass C, Sommerer F, Tannapfel A, Lippert H, Kockerling F. The use of composite meshes in laparoscopic repair of abdominal wall hernias: are there differences in biocompatibily? Experimental results obtained in a laparoscopic porcine model. Surg Endosc. 2009;23(3):487-95.

17. Eriksen JR, Gogenur I, Rosenberg J. Choice of mesh for laparoscopic ventral hernia repair. Hernia. 2007;11:481-92.

18. Harrell AG, Novistsky YW, Cristiano JA, Gersin KS, Norton HJ, Kercher KW, Heniford BT. Prospective histologic evaluation of intra-abdominal prosthetics four months after implantation in a rabbit model. Surg Endosc. 2007;21:1170-4.

19. Rosch R, Junge K, Schachtrupp A, Klinge U, Klosterhalfen B, Schumpelick V. Mesh implants in hernia repair. Inflammatory cell response in a rat model. Eur Surg Res. 2003;35 (5):445-50. 
20. Jansen PL, Kever M, Rosch R, Krott E, Jansen M, AlfonsoJaume A. Polymeric meshes induce zonal regulation of matrix metalloproteinase-2 gene expression by macrophages and fibroblasts. Faseb J. 2007;21(4):1047-57.

\section{Acknowledgments}

To Prof. Dr. Alcino Lázaro da Silva for his contribution with the Transpalb technique, the graduate students Pedro Álvares Henrique Paiva Macedo, Rodrigo Álvares Paiva Macedo and Marina Amaral Fonte Boa for helping in this study, and the University of Medical Sciences of Minas Gerais (FCMMG).

\section{Correspondence:}

Gaspar de Jesus Lopes Filho

Rua Original 156/11

05435-050 São Paulo - SP Brasil

Tel.: (55 11)5571-3626

gasparlopes@uol.com.br

Received: December 20, 2012

Review: February 21, 2013

Accepted: March 19, 2013

Conflict of interest: none

Financial source: none

${ }^{1}$ Research performed at Laboratory of the Experimental Surgical Research, Medical School, University of Medical Sciences of Minas Gerais (FCMMG), Belo Horizonte-MG, Brazil. Part of Master degree thesis, Postgraduate Program in Interdisciplinary Surgical Sciences, Paulista School of Medicine, Federal University of Sao Paulo (UNIFESP). Tutor: Gaspar de Jesus Lopes Filho. 